Esta revista forma parte del acervo de la Biblioteca Jurídica Virtual del Instituto de Investigaciones Jurídicas de la UNAM http://www.juridicas.unam.mx/

\title{
EL DERECHO A LA CONSULTA DE LOS PUEBLOS INDÍGENAS. A PROPÓSITO DE LA ACCIÓN DE INCONSTITUCIONALIDAD $31 / 2014$
}

\author{
Juan Ángel ARROYO KALIS*
}

\begin{abstract}
SUMARIO: I. Introducción. II. Objeto. III. Sujetos. IV. Base constitucional y derecho internacional de los derechos humanos. V. Jurisprudencia de la Corte Interamericana de Derechos Humanos. VI. Efectos. VII. Exigibilidad directa. VIII. La acción de inconstitucionalidad 31/2014. IX. Consideraciones finales. X. Bibliografía.
\end{abstract}

\section{INTRODUCCIÓN}

En México, los pueblos indígenas padecen, desde hace muchos años, una situación de evidente precariedad en el goce de los derechos humanos, particularmente de aquéllos de naturaleza económica, social y cultural, en comparación con el conjunto de otros grupos que igualmente forman parte del cuerpo social. ${ }^{1}$

\footnotetext{
* Maestro en derecho constitucional y derechos humanos, con mención honorífica, por la Universidad Panamericana.

1 Carpizo, Jorge, "Una clasificación de los derechos de la justicia social", en Bogdandy, Armin von et al. (coords.), Construcción y papel de los derechos sociales fundamentales. Hacia un ius constitutionale commune en América Latina, México, UNAM, Instituto de Investigaciones Jurídicas, Max-Planck-Institut für ausländisches öffentliches Recht und Völkerrecht, Instituto Iberoamericano de Derecho Constitucional, 2011, p. 437. Resulta importante precisar, desde este momento, que al hacer referencia en este ensayo al concepto de pueblos indígenas se entienden comprendidas las comunidades indígenas. En tal tesitura, la Constitución mexicana define a los pueblos indígenas, en su artículo 2o., párrafo segundo, como "aquellos que descienden de poblaciones que habitaban en el territorio actual del país al iniciarse la colonización y que conservan sus propias instituciones sociales, económicas, culturales y políticas, o parte de ellas", mientras que en el párrafo cuarto del mismo precepto se concibe a las comunidades indígenas como las integrantes
} 
Esta revista forma parte del acervo de la Biblioteca Jurídica Virtual del Instituto de Investigaciones Jurídicas de la UNAM

\section{JUAN ÁNGEL ARROYO KALIS}

Si bien se han tomado medidas gubernamentales para combatir tal circunstancia, como la creación en 2003 de la Comisión Nacional para el Desarrollo de los Pueblos Indígenas, en sustitución del Instituto Nacional Indigenista de 1948, lo cierto es que todas ellas han resultado endebles e insuficientes para superar los enormes retos que el país tiene frente a sí en esta materia.

Así, el sector indígena constituye un grupo vulnerable en razón del estado de marginación en el que se encuentra, el cual se manifiesta a partir de los bajos índices (con gran probabilidad los más bajos dentro de la población mexicana) en el disfrute de los derechos de educación, protección a la salud, alimentación, acceso a agua potable, vivienda decorosa, trabajo bien remunerado, entre otros tantos. ${ }^{2}$

Infortunadamente, el escenario de pobreza e indefensión en el que subsisten los pueblos indígenas no se circunscribe al ámbito del país, sino que representa un asunto de índole global. Para decirlo con las palabras de James Anaya:

En el mundo contemporáneo, los pueblos indígenas viven generalmente bajo condiciones de gran desventaja comparativa dentro de los estados que fueron construidos en torno a ellos. Los fenómenos históricos motivados por la discriminación racial no son meras injusticias del pasado,

de un pueblo indígena "que formen una unidad social, económica y cultural, asentadas en un territorio y que reconocen autoridades propias de acuerdo con sus usos y costumbres". Cabe decir que la primera de las definiciones transcritas es retomada del artículo 1.1, inciso b), del Convenio 169 sobre Pueblos Indígenas y Tribales en Países Independientes de la Organización Internacional del Trabajo, instrumento sobre el que se repara más adelante en este ensayo.

2 Ibidem, p. 439. Según datos aportados por el Instituto Nacional de Estadística y Geografía (INEGI) a través de la Encuesta Intercensal 2015, en México la población que se considera a sí misma indígena es de 25 millones 694 mil 928 personas, cantidad que representa el $21.5 \%$ de la población total del país, y se localiza principalmente en los estados de Oaxaca, Yucatán, Campeche y Quintana Roo. En lo concerniente al disfrute de derechos sociales, la encuesta señala, entre otras cuestiones, que el promedio de escolaridad en la población hablante de lenguas indígenas es de 5.7 años, mientras que a nivel nacional es de 9.1 años; asimismo, se apunta que el porcentaje de analfabetismo en esa población (de 15 años en adelante) es de $23 \%$, en tanto que en el ámbito nacional de $5.5 \%$.

Por otro lado, se advierte que 14 de cada 100 viviendas de la población que habla lenguas indígenas tiene piso de tierra, mientras que para el país la cifra es de 4 de cada 100 viviendas. Finalmente, la cobertura de agua entubada al interior de las viviendas de esa población es de $38.4 \%$, y a nivel nacional de $74.1 \%$. Los principales resultados de la Encuesta Intercensal 2015 elaborada por el INEGI se encuentran disponibles en: www.inegi.org.mx/est/contenidos/proyectos/encuestas/hogares/especiales/ei2015/doc/ eic_2015_presentacion.pdf 
Esta revista forma parte del acervo de la Biblioteca Jurídica Virtual del Instituto de Investigaciones Jurídicas de la UNAM

EL DERECHO A LA CONSULTA DE LOS PUEBLOS INDÍGENAS...

sino que se traducen en desigualdades presentes. Los pueblos indígenas se han visto privados de vastas extensiones de tierras y del acceso a los recursos necesarios para la subsistencia, y han padecido el efecto de las fuerzas que históricamente han procurado hacer desaparecer sus instituciones políticas y culturales. Como consecuencia, los pueblos indígenas han sido discriminados en términos económicos y sociales, su cohesión como comunidades se ha visto quebrantada o amenazada y la integridad de sus culturas ha sido socavada. Tanto en los estados industrializados como en los países en vía de desarrollo, los sectores indígenas se encuentran, casi invariablemente, en el último escalón de la escala socioeconómica y existen al margen del poder. ${ }^{3}$

Ante las desventajas que sufren los grupos vulnerables, surge indispensable dotarlos de facultades especiales que hagan efectivo su acceso a una igualdad real de oportunidades para que sus miembros puedan desarrollar un plan de vida en condiciones de dignidad. Se trata de derechos encaminados a disminuir la brecha de desigualdad que separa a dichos grupos del resto de la población. Es en este contexto donde cabe situar el derecho a la consulta de los pueblos indígenas, cuyos aspectos principales se describen en los apartados que continúan.

\section{OBJETo}

El derecho a la consulta se traduce en un derecho colectivo, puesto que pertenece al pueblo indígena en su conjunto, que tiene como propósito garantizar la participación del mismo en la toma de aquellas decisiones susceptibles de afectarlo. En otros términos, mediante el derecho a la consulta los pueblos indígenas cuentan con la posibilidad de manifestar sus opiniones, intereses y necesidades ante la autoridad pública siempre que ésta intente adoptar una determinación que pueda repercutir directamente en las condiciones de vida de tales pueblos.

De esta manera, se obliga al Estado (e indirectamente a los poderes privados que se encuentren involucrados en la decisión pública respectiva) a atender el sentir de los pueblos indígenas cuando se pretenda iniciar cualquier plan, proyecto, política o modificación legislativa que pueda perjudicarles. Así, el derecho a la consulta se presenta como una herramienta jurídica para hacer frente a la discrecionalidad y la arbitrariedad que tradicionalmente ha caracterizado el actuar del Estado en

3 Anaya, James, Los pueblos indígenas en el derecho internacional, Madrid, Trotta, UNIA, 2005, p. 25. 
Esta revista forma parte del acervo de la Biblioteca Jurídica Virtual del Instituto de Investigaciones Jurídicas de la UNAM

\section{JUAN ÁNGEL ARROYO KALIS}

relación con dichos grupos sociales, y al mismo tiempo asegurar que éstos puedan alzar la voz para formar parte de los procesos estatales de toma de decisiones. ${ }^{4}$

Como puede observarse, el derecho a la consulta se vincula estrechamente con el derecho a la participación política de los pueblos indígenas, pues, como se ha señalado, permite que éstos intervengan en la dirección de los asuntos públicos que puedan incidir en su desarrollo. De hecho, puede decirse, con razón, que el derecho a la consulta constituye uno de los cauces más importantes por medio de los cuales se ejerce la participación política de los pueblos indígenas a fin de que éstos se involucren, de forma real y efectiva, en las decisiones públicas que impacten directamente en su porvenir.

De modo similar, el derecho a la consulta se relaciona con el derecho a la libre determinación de los pueblos indígenas, debido a que impulsa su autonomía y les permite decidir por sí mismos sobre su destino mediante la intervención en las decisiones estatales que repercuten en sus condiciones de vida. ${ }^{5}$ No sobra advertir que la libre determinación de los pueblos indígenas no es ni puede ser absoluta, dado que, como la norma constitucional mexicana establece, deberá ser ejercida asegurando en todo momento la unidad nacional (artículo 2o., párrafo quinto). ${ }^{6}$

En suma, el derecho a la consulta representa un valioso instrumento para combatir la exclusión social a la que históricamente se han visto sometidos los pueblos indígenas en México, siendo relegados de los procesos que anteceden a la toma de las decisiones públicas, lo que resulta inadmisible sobre todo cuando se trata de aquellas decisiones que tienen que ver con las aspiraciones e intereses de esos pueblos. De

4 Gutiérrez Rivas, Rodrigo, "Derecho a la consulta de los pueblos indígenas en México: un primer acercamiento", en Ferrer Mac-Gregor, Eduardo y Zaldívar Lelo de Larrea, Arturo (coords.), La ciencia del derecho procesal constitucional. Estudios en homenaje a Héctor Fix-Zamudio en sus cincuenta años como investigador del derecho, México, UNAM, Instituto de Investigaciones Jurídicas-IMDPC-Marcial Pons, 2008, t. XII: Ministerio Público, contencioso administrativo y actualidad jurídica, pp. 539 y 540.

5 Sobre el tema, véase Aparicio Wilhelmi, Marco, "La libre determinación y la autonomía de los pueblos indígenas. El caso de México", Boletín Mexicano de Derecho Comparado, México, nueva serie, año XLII, núm. 124, enero-abril de 2009, pp. 13-38.

6 Como ha puntualizado la Suprema Corte de Justicia de la Nación, el reconocimiento del derecho a la libre determinación de los pueblos indígenas "no implica su independencia política ni su soberanía, sino sólo la posibilidad de elegir libremente su situación dentro del Estado mexicano, que no conduce a su disolución, sino al reconocimiento del derecho fundamental de los pueblos que lo componen para determinar su suerte, siempre y cuando se preserve la unidad nacional". Tesis 1a. XVI/2010, Semanario Judicial de la Federación y su Gaceta, Novena Época, t. XXXI, febrero de 2010, p. 114. 
Esta revista forma parte del acervo de la Biblioteca Jurídica Virtual del Instituto de Investigaciones Jurídicas de la UNAM

EL DERECHO A LA CONSULTA DE LOS PUEBLOS INDÍGENAS...

ahí la imperiosa necesidad de que el Estado reconozca esta facultad y garantice su ejercicio en aquellos casos en los que sea procedente.

\section{SUJETOS}

Es menester acentuar que la planificación y realización del proceso de consulta indígena es una obligación exclusiva del Estado, sin que tal responsabilidad pueda delegarse en terceros particulares. En consecuencia, el Estado no podría, por ejemplo, autorizar que una empresa interesada en la explotación de los recursos naturales en un territorio indígena sea la encargada de efectuar la consulta. ${ }^{7}$

Por otro lado, corresponde al pueblo indígena, no al Estado, determinar, de acuerdo con sus costumbres y tradiciones, quién o quiénes serán las personas que lo representen en cada proceso de consulta. Dicha decisión debe hacerse del conocimiento de la autoridad estatal con el objeto de que ésta lleve a cabo la consulta indígena sólo con tales representantes. ${ }^{8}$

\section{BASE CONSTITUCIONAL Y DERECHO INTERNACIONAL DE LOS DERECHOS HUMANOS}

En México, el derecho a la consulta tiene su base constitucional en el artículo 2o., apartado B, fracción IX, cuyo texto dispone que, para abatir las carencias y rezagos que afectan a los pueblos indígenas, las autoridades federales, de las entidades federativas y municipales deberán consultarlos "en la elaboración del Plan Nacional de Desarrollo y de los planes de las entidades federativas, de los Municipios (sic) y, cuando proceda, de las demarcaciones territoriales de la Ciudad de México y, en su caso, incorporar las recomendaciones y propuestas que realicen". ${ }^{9}$

7 Corte Interamericana de Derechos Humanos, sentencia del caso "Pueblo indígena Kichwa de Sarayaku vs. Ecuador" (fondo y reparaciones), 27 de junio de 2012, serie C, núm. 245, párrafo 187.

8 Corte Interamericana de Derechos Humanos, sentencia del caso "Pueblo Saramaka vs. Surinam" (interpretación de la sentencia de excepciones preliminares, fondo, reparaciones y costas), 12 de agosto de 2008, serie C, núm. 185, párrafos 18, 19 y 22.

9 Existe otra referencia al tema, ciertamente tangencial, dentro del artículo 2o., apartado B, fracción II de la Constitución federal, en donde se obliga a las autoridades mencionadas a definir y desarrollar programas educativos con contenido regional que reconozcan la herencia cultural de los pueblos indígenas, de acuerdo con las leyes de la materia y en consulta con las comunidades indígenas. 
Esta revista forma parte del acervo de la Biblioteca Jurídica Virtual del Instituto de Investigaciones Jurídicas de la UNAM

\section{JUAN ÁNGEL ARROYO KALIS}

Se trata de un enunciado escueto, con alcances limitados, ya que contempla el ejercicio del multicitado derecho únicamente dentro del procedimiento de elaboración del Plan Nacional de Desarrollo, así como de sus equivalentes en el ámbito de las entidades federativas y municipios. En la misma lógica, cabe destacar que en el precepto constitucional de mérito no se prevén los principios básicos que deben regir el derecho a la consulta, cuestión que es menester corregir sobre todo por motivos de seguridad jurídica para con los pueblos indígenas del país.

Sin dejar de lado la necesidad de reformar este precepto con el objeto de ampliar los alcances del derecho en cuestión y delimitar sus características esenciales, lo cierto es que es en el derecho internacional de los derechos humanos donde se localiza un desarrollo normativo más detallado del derecho a la consulta.

Como bien sostiene Rodrigo Gutiérrez Rivas, es en el derecho internacional de los derechos humanos donde la presión política de amplias redes de pueblos indígenas de todo el mundo ha logrado el reconocimiento jurídico de derechos específicos para sus comunidades (entre los que se ubica el derecho a la consulta) que hoy pueden invocarse al interior de los Estados para defender los intereses y necesidades que forman parte de la agenda indígena..$^{10}$

Dentro de tal entorno, el Convenio 169 sobre Pueblos Indígenas y Tribales en Países Independientes de la Organización Internacional del Trabajo (OIT) ${ }^{11}$ se erige como "el principal referente internacional especializado sobre la protección de los derechos y la integridad de los pue-

10 Gutiérrez Rivas, Rodrigo, op. cit., nota 4, p. 536. En sentido similar, James Anaya señala que: "El sistema internacional contemporáneo reconoce abiertamente ahora que es un imperativo de derechos humanos el dar respuesta a las demandas de los pueblos indígenas. Este reconocimiento ha dado lugar al esfuerzo sostenido de las instituciones internacionales en favor de los pueblos indígenas, así como a la aparición de un conjunto de normas que desarrollan los principios de derechos humanos ya existentes en relación con estos pueblos... [P]uede hablarse ahora de un régimen de derechos indígenas dentro del derecho internacional de los derechos humanos; un régimen todavía en desarrollo y que, en cierta medida, beneficia a los pueblos indígenas". Anaya, James, op. cit., nota 3 , p. 30.

11 Adoptado el 27 de junio de 1989 durante la septuagésima sexta reunión de la Conferencia Internacional del Trabajo (CIT), celebrada en Ginebra, Suiza, entrando en vigor el 5 de septiembre de 1991. Cabe mencionar que este convenio es producto de la revisión del Convenio 107 sobre Poblaciones Indígenas y Tribuales de la misma organización (1957). El Convenio 169 de la OIT fue publicado en el Diario Oficial de la Federación el 24 de enero de 1991; el texto completo de este instrumento internacional puede ser consultado en la siguiente dirección: www.ilo.org/dyn/normlex/es/f?p=NORMLEXPUB:12100:0::NO:1 2100:P12100_ILO_CODE:C169. 
Esta revista forma parte del acervo de la Biblioteca Jurídica Virtual del Instituto de Investigaciones Jurídicas de la UNAM

EL DERECHO A LA CONSULTA DE LOS PUEBLOS INDÍGENAS...

blos indígenas y, particularmente, de la consulta a éstos en aquello que les afecte directamente". ${ }^{12}$

En este orden, el artículo 6.1, inciso a, del citado instrumento internacional impone a los Estados parte, la obligación de "consultar a los pueblos [indígenas y tribales] interesados, mediante procedimientos apropiados y en particular a través de sus instituciones representativas, cada vez que se prevean medidas legislativas o administrativas susceptibles de afectarles directamente".

Como puede verse, el precepto que se acaba de transcribir no restringe o acota a determinados temas la obligación que poseen los Estados parte de consultar a los pueblos indígenas que se encuentren bajo su jurisdicción; por el contrario, es claro que el Convenio 169 de la OIT ordena que la consulta indígena se lleve a cabo en cada ocasión en la que un Estado parte pretenda adoptar una medida, sea ésta de naturaleza legislativa o administrativa, que pueda afectar de forma directa a los pueblos indígenas sujetos a su jurisdicción. ${ }^{13}$

Aunado a lo anterior es pertinente indagar qué derechos de los pueblos indígenas tendrían que estar en riesgo para que el Estado deba realizar una consulta. A la luz de lo dispuesto por el Convenio no se advierte limitación alguna al respecto, por lo que es dable sostener que si bien el derecho a la consulta se ha identificado comúnmente con los derechos a la tierra y sus recursos naturales a causa del acoso de intereses empresariales nacionales e internacionales, debe comprender todos los derechos reconocidos a los pueblos indígenas, sean territoriales, sociales, políticos, culturales, jurisdiccionales, etcétera. ${ }^{14}$

Es importante tener presente que la obligación de un Estado de consultar a los pueblos indígenas no depende de que se compruebe una

12 Romero Pérez, Xiomara y Rosas Martínez, Alejandro, "Implementación de la consulta previa en Colombia y su debate actual. A propósito de los pueblos indígenas y tribales", en Macías Vázquez, María del Carmen y Anglés Hernández, Marisol (coords.), Estudios en homenaje a don José Emilio Rolando Ordóñez Cifuentes, México, UNAM, Instituto de Investigaciones Jurídicas, 2013, p. 26.

13 De modo ejemplificativo, la SCJN ha enunciado algunas situaciones genéricas en las que el Estado debe consultar a los pueblos indígenas, a saber: la pérdida de territorios y tierra tradicional; el desalojo de sus tierras; el posible reasentamiento; el agotamiento de recursos necesarios para la subsistencia física y cultural; la destrucción y contaminación del ambiente tradicional; la desorganización social y comunitaria, y los impactos negativos sanitarios y nutricionales en tales pueblos. Cfr. Tesis 2a. XXVII/2016 (10a.), Gaceta del Semanario Judicial de la Federación, Décima Época, libro 31, t. II, junio de 2016, p. 1213.

14 González Galván, Jorge Alberto, "Derecho indígena: consulta y participación ciudadana", en Carbonell, Miguel y Cruz Barney, Oscar (coords.), Historia y Constitución. Estudios en homenaje a José Luis Soberanes Fernández, México, UNAM, Instituto de Investigaciones Jurídicas, 2015, t. I, p. 213. 
Esta revista forma parte del acervo de la Biblioteca Jurídica Virtual del Instituto de Investigaciones Jurídicas de la UNAM

\section{JUAN ÁNGEL ARROYO KALIS}

afectación real a sus derechos, sino de que exista la posibilidad de que los mismos lleguen a ser vulnerados, ya que uno de los objetivos que se persiguen con el procedimiento de consulta es justamente determinar si los derechos de los pueblos indígenas se verían perjudicados a partir de la medida que se desea adoptar. ${ }^{15}$

Junto al Convenio 169 de la OIT es preciso referir, asimismo, la Declaración de las Naciones Unidas sobre los Derechos de los Pueblos Indígenas ${ }^{16}$ que, aunque no constituye un instrumento vinculante para el Estado mexicano, como sí sucede en el caso del Convenio, también resulta de considerable trascendencia para impulsar el reconocimiento y garantía del derecho a la consulta indígena en el país.

En lo que interesa, esta Declaración contribuye en buena medida al cumplimiento del Convenio 169 de la OIT, profundizando sobre diversas de sus disposiciones relativas a la vigencia y protección de los derechos colectivos que asisten a los pueblos indígenas para decidir libremente sobre cuestiones de carácter interno.

Con una redacción bastante similar a la del Convenio 169 de la OIT, el artículo 19 de la Declaración establece que: "Los Estados celebrarán consultas y cooperarán de buena fe con los pueblos indígenas interesados por medio de sus instituciones representativas antes de adoptar y aplicar medidas legislativas o administrativas que los afecten, a fin de obtener su consentimiento libre, previo e informado".

\section{JURISPRUDENCIA DE LA CORTE INTERAMERICANA DE DERECHOS HUMANOS}

En ejercicio de su competencia contenciosa, la Corte Interamericana de Derechos Humanos (Corte IDH) ha trazado significativas directrices respecto a los elementos característicos del derecho a la consulta de los pueblos indígenas. ${ }^{17}$

15 Tesis 1a. CCXXXVI/2013 (10a.), Semanario Judicial de la Federación y su Gaceta, Décima Época, libro XXIII, t. 1, agosto de 2013, p. 736.

16 Adoptada por la Asamblea General de la Organización de las Naciones Unidas (ONU) el 13 de septiembre de 2007, mediante resolución 61/295. El texto completo de este instrumento internacional puede verse en: www.un.org/esa/socdev/unpfii/documents/ DRIPS_es.pdf

17 Aunque pueda considerarse una obviedad, no sobra decir que la jurisprudencia de la Corte IDH es vinculante para el Estado mexicano, incluso cuando se trate de criterios que hayan derivado de casos donde no haya sido parte en el litigio respectivo, en razón de que conforma una extensión de la Convención Americana sobre Derechos Humanos. Por eso se puede estar de acuerdo con Néstor Pedro Sagüés, quien afirma que "las líneas 
Esta revista forma parte del acervo de la Biblioteca Jurídica Virtual del Instituto de Investigaciones Jurídicas de la UNAM

EL DERECHO A LA CONSULTA DE LOS PUEBLOS INDÍGENAS...

En primer término, la Corte IDH ha señalado que la consulta que realice el Estado debe ser previa, es decir, debe llevarse a cabo antes de que se adopte la medida que pueda afectar a determinado pueblo indígena, con el objeto de que éste se vea involucrado lo antes posible en el proceso de deliberación correspondiente. ${ }^{18}$

En lo relativo a medidas administrativas, como planes de desarrollo o inversión, la consulta debe efectuarse durante sus primeras etapas, debido a que el aviso temprano a los pueblos indígenas "permite un tiempo adecuado para la discusión interna dentro de las comunidades y para brindar una adecuada respuesta al Estado"; 19 en tratándose de medidas legislativas, "los pueblos indígenas deberán ser consultados previamente en todas las fases del proceso de producción normativa, y dichas consultas no deben ser restringidas a propuestas". ${ }^{20}$

Se trata de un elemento de la mayor relevancia, en tanto que su inobservancia vaciaría de contenido la finalidad de la consulta indígena; de poco o nada sirve consultar a los pueblos interesados cuando la medida en cuestión ya fue adoptada, o peor aún ejecutada, ocasionando una afectación irreparable en las condiciones de vida de tales pueblos. Además, si, como se ha sostenido, el derecho a la consulta pretende servir como una herramienta para combatir la exclusión social a la que se han visto históricamente sometidos los pueblos indígenas en el proceso de toma de decisiones públicas, máxime de aquéllas que puedan vulnerarlos, es lógico concluir que el ejercicio de este derecho debe ser garantizado de forma previa, con suficiente antelación a la adopción de la medida estatal, nunca después.

Como segundo elemento característico, la Corte IDH ha indicado que el proceso de consulta a los pueblos indígenas debe realizarse de buena fe y con el propósito de lograr un acuerdo. Esto significa que la consulta indígena que efectúe el Estado no debe suponer para éste una cuestión de trámite o un mero formalismo, sino que debe ser concebida

jurisprudenciales de la Corte Interamericana han dejado de ser meras guías, o criterios de interpretación, o directrices de innegable conocimiento, para convertirse, en particular después del enunciado de la doctrina del "control de convencionalidad", en reglas de derecho positivo". Sagüés, Néstor Pedro, La Constitución bajo tensión, México, Instituto de Estudios Constitucionales del Estado de Querétaro, 2016, p. 456.

18 Corte IDH, sentencia del caso "Pueblo indígena Kichwa de Sarayaku vs. Ecuador" (fondo y reparaciones), párrafo 181. Este elemento se refleja claramente en el contenido del artículo 19 de la Declaración de las Naciones Unidas sobre los Derechos de los Pueblos Indígenas (DNUDPI), antes transcrito.

19 Ibidem, párrafo 180.

20 Ibidem, párrafo 181. 
Esta revista forma parte del acervo de la Biblioteca Jurídica Virtual del Instituto de Investigaciones Jurídicas de la UNAM

\section{JUAN ÁNGEL ARROYO KALIS}

como un mecanismo que permita entablar un diálogo con el pueblo indígena de que se trate en un ambiente de confianza y respeto mutuo, en aras de generar un acuerdo satisfactorio para ambas partes. ${ }^{21}$

En adición a lo anterior, la Corte Interamericana también ha resaltado que la buena fe "exige la ausencia de cualquier tipo de coerción por parte del Estado o de agentes o terceros que actúan con su autorización o aquiescencia". ${ }^{22}$ Igualmente, enfatiza que una consulta realizada de buena fe "es incompatible con prácticas tales como los intentos de desintegración de la cohesión social de las comunidades afectadas, sea a través de la corrupción de los líderes comunales o del establecimiento de liderazgos paralelos, o por medio de negociaciones con miembros individuales de las comunidades que son contrarias a los estándares internacionales". 23

En beneficio de la inclusión y desarrollo de los pueblos indígenas es necesario que no exista cabida para la simulación, la malicia o la reticencia durante el proceso de consulta. Por el contrario, surge indispensable la disposición permanente, no sólo del Estado sino también del pueblo indígena, para que la consulta se despliegue en óptimas condiciones que permitan arribar a un acuerdo que satisfaga en la mayor medida posible los intereses de las partes.

Así, por ejemplo, el Estado debe estar dispuesto a modificar e incluso cancelar la medida que propone a la luz del resultado que arroje la consulta, tomando en consideración los argumentos del pueblo indígena. A su turno, el pueblo indígena debe evitar las posturas adversas al diálogo, mostrando el interés de ser consultado para exponer, en su caso, las razones por las que no coincide con la medida estatal, así como los cambios que tendrían que realizarse a la misma para ser aceptada.

En suma, deben realizarse esfuerzos conjuntos a fin de que el proceso de consulta se traduzca en un auténtico ejercicio de diálogo y negociación en el que se exploren las alternativas que conduzcan al con-

21 Ibidem, párrafo 186. Esta característica encuentra sustento en el artículo 6.2 del Convenio 169 de la OIT, que dice: "Las consultas llevadas a cabo en aplicación de este Convenio deberán efectuarse de buena fe y de una manera apropiada a las circunstancias, con la finalidad de llegar a un acuerdo o lograr el consentimiento acerca de las medidas propuestas". En el mismo orden, el precepto 32.2 de la DNUDPI menciona: "Los Estados celebrarán consultas y cooperarán de buena fe con los pueblos indígenas interesados por conducto de sus propias instituciones representativas a fin de obtener su consentimiento libre e informado antes de aprobar cualquier proyecto que afecte a sus tierras o territorios y otros recursos, particularmente en relación con el desarrollo, la utilización o la explotación de recursos minerales, hídricos o de otro tipo".

22 Idem.

23 Idem. 
Esta revista forma parte del acervo de la Biblioteca Jurídica Virtual del Instituto de Investigaciones Jurídicas de la UNAM

EL DERECHO A LA CONSULTA DE LOS PUEBLOS INDÍGENAS...

senso sobre la medida estatal que se desea ejecutar, protegiendo los derechos e intereses de los pueblos indígenas $\mathrm{y}$, consecuentemente, de sus integrantes.

En esta forma se abona a la construcción de una relación de entendimiento entre el Estado y los pueblos indígenas sobre asuntos ciertamente complejos que, abordados de otra manera, podrían generar graves conflictos e incluso desembocar en escenarios de violencia. De ahí la conveniencia de procurar un entorno de mediación a efecto de encauzar la solución de disputas y prevenir la toma de posiciones extremas. Además, un acuerdo que derive de un proceso de negociación basado en un diálogo de buena fe, que tenga como objetivo alcanzar un acuerdo, contará con un alto grado de legitimidad no sólo ante los actores involucrados en la consulta, sino frente a la sociedad en su conjunto. ${ }^{24}$

El tercer elemento característico al que alude la Corte IDH consiste en que la consulta se formule de manera adecuada y accesible. En esta tesitura, resulta preciso que las consultas indígenas se hagan a través de procedimientos culturalmente adecuados, es decir, de acuerdo con las propias costumbres y tradiciones de los pueblos indígenas. ${ }^{25}$

Para ello es imprescindible que el Estado respete los procesos internos que sigan los pueblos indígenas para adoptar una determinación en torno a la medida que se les consulte (los cuales, por lo general, se desarrollan a través de sus instituciones representativas, como las asambleas o los consejos). Lo anterior, siempre que en tales procesos no se transgredan los derechos humanos, pues de lo contrario no podrán ser reconocidos por la autoridad estatal. 26

Es pertinente destacar que no existe un modelo único de procedimiento apropiado para realizar la consulta indígena; por ende, el Estado debe atender en cada caso las circunstancias nacionales y del pueblo en cuestión, así como la naturaleza de la medida sobre la que verse la consulta a efectuar. ${ }^{27}$

Finalmente, el cuarto elemento característico indica que la consulta sea informada, esto es, que los pueblos indígenas tengan conocimien-

24 Anaya, James, op. cit., nota 3, pp. 246 y 247.

25 Corte IDH, sentencia del caso "Pueblo indígena Kichwa de Sarayaku vs. Ecuador" (fondo y reparaciones), párrafo 201. Este aspecto se encuentra igualmente reconocido en el artículo 6.1, inciso a), del Convenio 169 de la OIT, antes citado.

26 Piénsese, por ejemplo, en aquellos procesos internos en los que las mujeres indígenas no cuentan con voz ni voto en la deliberación de los asuntos concernientes al pueblo indígena.

27 Corte IDH, sentencia del caso "Pueblo indígena Kichwa de Sarayaku vs. Ecuador" (fondo y reparaciones), párrafo 202. 
Esta revista forma parte del acervo de la Biblioteca Jurídica Virtual del Instituto de Investigaciones Jurídicas de la UNAM

\section{JUAN ÁNGEL ARROYO KALIS}

to de los posibles riesgos que conlleva la medida que el Estado desea implementar. Para tal efecto, la autoridad estatal debe proporcionar, a través de una comunicación constante con el pueblo indígena, información suficiente, completa, comprensible, veraz y oportuna respecto a la naturaleza y eventuales consecuencias de la medida. ${ }^{28}$

En cualquier caso, la información que se brinde deberá estar traducida al idioma o lengua del pueblo indígena, así como carecer de tecnicismos innecesarios.

Como puede verse, en este tema la información reviste especial trascendencia. La información en poder del Estado es fundamental para que el pueblo indígena pueda tomar, en conciencia y con pleno conocimiento, una decisión adecuada que proteja de la mejor manera sus intereses y derechos frente a la medida estatal, sobre todo si se tiene en cuenta que, según su magnitud, esa medida puede tener un impacto irreversible o generar daños irreparables en las condiciones de vida y planes de dicho pueblo.

\section{EFECTOS}

Expuesto lo anterior, conviene detenerse en un aspecto central, sobre el que aún no existe criterio uniforme, que guarda relación con los efectos de la consulta indígena. En concreto, la cuestión estriba en determinar si la respuesta que emita un pueblo indígena como resultado de la consulta que se realice resulta vinculante para el Estado respecto a la medida que se desea implementar. Más aún, ¿cuentan los pueblos indígenas con un derecho de veto sobre la medida estatal que se les consulte cuando no estén de acuerdo con la ejecución de la misma?

En este punto, sin duda polémico, se considera que la respuesta de un pueblo indígena después de haber sido consultado no puede ser vinculante para el Estado sobre la realización de la medida administrativa o legislativa de que se trate. Por ende, los pueblos indígenas no poseen la facultad de prohibir o impedir, por sí mismos, la implementación de la medida estatal que les sea consultada.

En definitiva, el actuar del Estado no puede quedar subordinado a la voluntad de los pueblos indígenas, por ejemplo, en planes, proyectos o leyes de desarrollo urbano que se quieran impulsar en beneficio del interés público. ${ }^{29}$

28 Ibidem, párrafo 208.

29 Una postura distinta es la que sostiene Jorge Alberto González Galván, argumentando que los efectos de la consulta indígena deben ser obligatorios para las autoridades 
Esta revista forma parte del acervo de la Biblioteca Jurídica Virtual del Instituto de Investigaciones Jurídicas de la UNAM

EL DERECHO A LA CONSULTA DE LOS PUEBLOS INDÍGENAS...

En este sentido, si bien el Convenio 169 de la OIT dispone en su artículo 6.2 que las consultas indígenas deben efectuarse "con la finalidad de llegar a un acuerdo o lograr el consentimiento acerca de las medidas propuestas", lo cierto es que ello no se traduce en una exigencia para que las consultas arriben a un acuerdo ni mucho menos para que se obtenga el consentimiento del pueblo indígena en todos los casos. Esta interpretación ha sido sostenida por los órganos de la propia OIT. ${ }^{30}$

El acuerdo entre las partes debe ser visto como una aspiración permanente, como el objetivo último al que deben destinarse todos los esfuerzos posibles tanto del Estado como del pueblo indígena durante el proceso de consulta, con independencia del resultado que finalmente se obtenga.

Para James Anaya el requisito previsto en el Convenio 169 de la OIT relativo a que las consultas deben tender a la consecución de un acuerdo entre las partes significa que las consultas no pueden consistir simplemente en informar o notificar a los pueblos indígenas sobre las medidas susceptibles de afectarles. Los procedimientos de consulta, afirma Anaya, deben ser diseñados de forma que concedan a los pueblos indígenas la oportunidad de influir de manera efectiva en las decisiones que puedan afectar sus intereses, para lo cual es debido que el gobierno entable un diálogo con tales pueblos sobre las probables consecuencias de esas decisiones antes de que las mismas sean tomadas. ${ }^{31}$

En efecto, como se ha señalado párrafos atrás, la consulta indígena que realice el Estado no puede ser entendida por éste como una cuestión menor, como un mero formalismo; por el contrario, debe ser concebida como un mecanismo que permita mantener un diálogo cercano con los pueblos indígenas en un ambiente de confianza y respeto mutuo con el ánimo de alcanzar un acuerdo, aunque esto último no sea requisito indispensable para estimar válida dicha consulta.

La finalidad de la consulta indígena consiste precisamente en garantizar que antes de que se adopte una medida administrativa o legislativa que pueda afectar a un pueblo indígena se otorgue al mismo la oportunidad de que manifieste sus opiniones, dudas e inquietudes ante la autoridad pública, combatiendo así la exclusión social a la que históricamente se han visto sometidos tales pueblos. De tal suerte, se constriñe al Estado a atender la postura del pueblo indígena en relación con

estatales, garantizando así el desarrollo de los pueblos indígenas; si esto no fuese así, según este autor, la indefensión e inseguridad jurídica de tales pueblos se vería acentuada. Cfr. González Galván, Jorge Alberto, op. cit., nota 14, p. 215.

30 Anaya, James, op. cit., nota 3, pp. 234 y 235.

31 Ibidem, p. 235. 
Esta revista forma parte del acervo de la Biblioteca Jurídica Virtual del Instituto de Investigaciones Jurídicas de la UNAM

\section{JUAN ÁNGEL ARROYO KALIS}

la medida que se intenta implementar, pero no a actuar de conformidad con lo que ese pueblo exprese.

Ahora bien, en el caso de que el pueblo indígena no esté de acuerdo con la medida y el Estado aún decida ejecutarla, éste deberá justificar su proceder expresando las razones por las que no se conduce conforme a los resultados de la consulta. En específico, la autoridad estatal debe acreditar que las restricciones que supone la medida propuesta para los derechos del pueblo indígena cumplen con lo dispuesto por el principio de proporcionalidad.

Con base en el principio de proporcionalidad se asegura que la intensidad de una restricción o el medio para su aplicación sea el indispensable para hacerla efectiva, lo que permite que el límite en cuestión cumpla su función (que consiste en negar la protección constitucional a determinada conducta que se pretende encuadrada en el objeto de un derecho) sin transgredir el contenido esencial del derecho de que se trate. Bajo tal esquema, el fin último de este principio consiste en evitar que el órgano de autoridad que tenga atribuida la facultad de imponer límites a un derecho fundamental vulnere, en su aplicación, el contenido esencial del mismo. ${ }^{32}$

En este orden, para demostrar que una medida de carácter restrictivo a un derecho humano atiende lo dispuesto por este principio es preciso llevar a cabo un examen o test de proporcionalidad, a través del cual se verifique si tal medida satisface los tres subprincipios que componen el principio de proporcionalidad, a saber: a) subprincipio de idoneidad, de conformidad con el cual la restricción debe perseguir un objetivo constitucionalmente legítimo y representar un medio adecuado

32 Villaverde Menéndez, Ignacio, "La resolución de conflictos entre derechos fundamentales. El principio de proporcionalidad", en Varios autores, El principio de proporcionalidad y la interpretación constitucional, Quito, Ministerio de Justicia y Derechos Humanos, 2008 , p. 182. En relación con el contenido esencial de los derechos fundamentales, el Tribunal Constitucional español ha establecido que el mismo se compone por "aquellas facultades o posibilidades de actuación necesarias para que el derecho sea recognoscible como pertinente al tipo descrito y sin las cuales deja de pertenecer a ese tipo y tiene que pasar a quedar comprendido en otro desnaturalizándose, por decirlo así. Todo ello referido al momento histórico de que en cada caso se trata y a las condiciones inherentes en las sociedades democráticas, cuando se trate de derechos constitucionales". Por tanto, se puede hablar de una esencialidad del contenido del derecho para hacer referencia a "aquella parte del contenido del derecho que es absolutamente necesaria para que los intereses jurídicamente protegibles, que dan vida al derecho, resulten real, concreta y efectivamente protegidos. De este modo, se rebasa o se desconoce el contenido esencial cuando el derecho queda sometido a limitaciones que lo hacen impracticable, lo dificultan más allá de lo razonable o lo despojan de la necesaria protección". Tribunal Constitucional de España, sentencia 11/1981, 8 de abril de 1981, fundamento jurídico 8. 
Esta revista forma parte del acervo de la Biblioteca Jurídica Virtual del Instituto de Investigaciones Jurídicas de la UNAM

EL DERECHO A LA CONSULTA DE LOS PUEBLOS INDÍGENAS...

para el logro del mismo; b) subprincipio de necesidad, según el cual la restricción debe ser indispensable para la obtención de ese objetivo, siempre que no exista un medio igualmente eficaz pero menos limitativo del derecho en cuestión, y c) subprincipio de proporcionalidad en sentido estricto, de acuerdo con el cual debe existir un claro equilibrio entre los beneficios que se obtienen con la medida restrictiva y los daños que esa medida ocasiona en el derecho fundamental respectivo. ${ }^{33}$

En síntesis, como indica la Corte Constitucional de Colombia, cuando no sea posible lograr el acuerdo o la concertación con el pueblo indígena, la decisión de la autoridad estatal debe ser razonable, objetiva y proporcionada, es decir, debe estar desprovista de arbitrariedad o autoritarismo. ${ }^{34}$

Aunado a lo anterior, huelga decir que, en todo caso, la decisión que se adopte estará sujeta a revisión por parte de las instancias administrativas o judiciales que corresponda para que, a través de procedimientos adecuados y efectivos, se evalúe la validez y pertinencia de las razones manifestadas por la autoridad para justificar la ejecución de la medida administrativa o legislativa, así como el equilibro entre los derechos e intereses que se encuentren involucrados. ${ }^{35}$

No se desconoce que, pese a todo lo dicho, la Corte IDH estableció, al resolver el caso Pueblo Saramaka vs. Surinam, que cuando se trate de planes de desarrollo, inversión, exploración o extracción a gran escala que puedan tener un impacto profundo en la integridad de las tierras y recursos naturales de un pueblo indígena, el Estado está obligado no sólo a consultarlo, sino también a obtener su consentimiento libre, informado y previo, según sus costumbres y tradiciones. ${ }^{36}$ Cabe esperar que este pronunciamiento sea detallado a través de posteriores resoluciones en la materia.

33 Para profundizar en este tema, véanse Cárdenas Gracia, Jaime, "Noción, justificación y críticas al principio de proporcionalidad", Boletín Mexicano de Derecho Comparado, México, nueva serie, año XLVII, núm. 139, enero-abril de 2014, pp. 65-100, y Bernal Pulido, Carlos, El principio de proporcionalidad y los derechos fundamentales, 3a. ed., Madrid, CEPC, 2007.

34 Corte Constitucional de Colombia, sentencia SU-039/97, 3 de febrero de 1997, apartado II: consideraciones de la Corte, 3.3. Citado por Romero Pérez, Xiomara y Rosas Martínez, Alejandro, op. cit., nota 12, p. 32.

35 Comisión Interamericana de Derechos Humanos, Derechos de los pueblos indígenas y tribales sobre sus tierras ancestrales y recursos naturales. Normas y jurisprudencia del sistema interamericano de derechos humanos, OEA/Ser.L/V/II, 30 de diciembre de 2009, párrafo 328.

36 Corte IDH, sentencia del caso "Pueblo Saramaka vs. Surinam" (excepciones preliminares, fondo, reparaciones y costas), 28 de noviembre de 2007, serie C, núm. 172, párrafos 134-137. 
Esta revista forma parte del acervo de la Biblioteca Jurídica Virtual del Instituto de Investigaciones Jurídicas de la UNAM

\section{EXIGIBILIDAD DIRECTA}

Recientemente, la Comisión Nacional de los Derechos Humanos (CNDH) emitió su Recomendación General 27/2016 en la que destacó la ausencia de normatividad interna en el país en materia de derecho a la consulta de los pueblos indígenas. ${ }^{37}$

En dicha Recomendación, la CNDH advierte que "[l]a falta de un ordenamiento específico que regule adecuadamente el proceso de consulta, tiene diversas consecuencias, principalmente, impide conocer de manera clara y precisa el contenido y alcance de los derechos de los pueblos indígenas sobre sus tierras, territorios y recursos naturales, entorpece la eficacia del procedimiento de consulta previa, libre e informada, y afecta en los planes de participación de los beneficios". ${ }^{38}$

Asimismo, plantea que "la articulación de una ley de consulta permitiría establecer procedimientos de consulta que tengan los estándares de protección más altos y vinculen a las autoridades para garantizar este derecho y en consecuencia proteger otros derechos íntimamente conectados como el de propiedad colectiva, identidad cultural, medio ambiente sano, etcétera". 39

En coincidencia con la CNDH, no se puede dejar de admitir la relevancia que guarda la emisión de una norma que prevea y desarrolle los elementos esenciales del derecho a la consulta indígena en aras de impulsar su cabal ejercicio en el país (los que se encuentran establecidos principalmente en el derecho internacional de los derechos humanos, como ha quedado expuesto párrafos atrás).

Empero, también debe quedar claro que esta situación no impide, desde luego, que el ejercicio del derecho a la consulta se deba garantizar a los pueblos indígenas en el país. Así, con independencia de que exista o no una ley reglamentaria en la materia, los pueblos indígenas cuentan con la facultad de exigir que se respete y garantice su derecho a la consulta en aquellos casos en los que resulte procedente su ejercicio. De lo contrario, se estaría incumpliendo lo dispuesto por el derecho

37 CNDH, Recomendación General 27/2016, 11 de julio de 2016; disponible en: www. cndh.org.mx/sites/all/doc/Recomendaciones/generales/RecGral_027.pdf. Esta situación encuentra un par de excepciones en los estados de San Luis Potosí y Durango, que cuentan con leyes sobre el derecho a la consulta indígena; sin embargo, la $\mathrm{CNDH}$ subraya la necesidad de que en ambas entidades federativas se analicen e integren los parámetros desarrollados en la Recomendación de mérito en las normas locales respectivas. Ibidem, párrafo 41.

38 Ibidem, párrafo 139.

39 Ibidem, párrafo 140. 
Esta revista forma parte del acervo de la Biblioteca Jurídica Virtual del Instituto de Investigaciones Jurídicas de la UNAM

EL DERECHO A LA CONSULTA DE LOS PUEBLOS INDÍGENAS...

internacional de los derechos humanos y, en concreto, por el Convenio 169 de la OIT y la jurisprudencia interamericana, ambos vinculantes para el Estado mexicano, como ya se ha dicho.

\section{LA ACCIÓN DE INCONSTITUCIONALIDAD 31/2014}

El 8 de marzo de 2016, el Pleno de la Suprema Corte de Justicia de la Nación (SCJN) resolvió la acción de inconstitucionalidad 31/2014, promovida por la Comisión Estatal de Derechos Humanos de San Luis Potosí, a través de su presidente, en contra del párrafo quinto del artículo 27 de la Ley para el Instituto de Desarrollo Humano y Social de los Pueblos y Comunidades Indígenas de la referida entidad federativa (INDEPI o Instituto, en lo sucesivo). ${ }^{40}$

El párrafo en cuestión, incorporado mediante decreto publicado en el Periódico Oficial del estado el 29 de mayo de 2014, indicaba que los diputados de la Comisión de Asuntos Indígenas del Congreso local pasarían a formar parte del Consejo Consultivo del INDEPI. ${ }^{41}$

Al respecto, la Comisión Estatal consideró, entre otras cuestiones, que ello constituía una intromisión directa e injustificada en el Consejo

40 Conviene recordar que en términos de lo dispuesto por el inciso g) de la fracción II del artículo 105 constitucional, los organismos estatales de protección de los derechos humanos se encuentran facultados para promover acciones de inconstitucionalidad en contra de leyes expedidas por las legislaturas locales que vulneren los derechos humanos previstos en la Constitución federal y en los tratados internacionales de los que sea parte el Estado mexicano.

41 El artículo 27 de la Ley para el INDEPI establecía lo siguiente:

"El Consejo Consultivo se integrará de la siguiente forma:

Por ciudadanos o ciudadanas con conocimientos y experiencia en materia de derechos y cultura indígena propuestos por las comunidades indígenas mediante el procedimiento siguiente: en cada uno de los municipios con presencia indígena acreditada mediante el padrón de comunidades existente, se convocará a mujeres y hombres propuestos mediante asamblea comunitaria, jueces auxiliares y comisariados ejidales de las comunidades indígenas para que en una sesión libre y de conformidad a sus procedimientos, elijan a un representante titular y un suplente, uno debe ser hombre y otro mujer y nunca del mismo género; para ser propuesto al nombramiento como integrante al Consejo Consultivo del Instituto, lo cual será definido por la Junta Directiva, de conformidad a la convocatoria que al efecto se expida en términos del reglamento interior del Instituto.

El número total de integrantes del Consejo Consultivo será determinado por la Junta Directiva, pero en ningún caso podrá ser menor a 24 miembros.

Si el representante titular del Instituto es hombre, el suplente de éste será mujer, y viceversa.

Además, se integrará al Consejo Consultivo, a los diputados de la Comisión de Asuntos Indígenas del Honorable Congreso del Estado de San Luis Potosi" (énfasis añadido). 
Esta revista forma parte del acervo de la Biblioteca Jurídica Virtual del Instituto de Investigaciones Jurídicas de la UNAM

\section{JUAN ÁNGEL ARROYO KALIS}

Consultivo, dado que no se consultó previamente a las comunidades indígenas con representación en el mismo, situación que resulta contraria a lo establecido en la Constitución federal (artículo 20., apartado B, fracción IX), así como en el Convenio 169 de la OIT (artículo 6o., inciso a, instrumento suscrito y ratificado por el Estado mexicano. ${ }^{42}$

En otras palabras, la Comisión invocó una violación en el proceso legislativo del cual derivó la disposición normativa impugnada, al no haberse respetado el derecho a la consulta de las comunidades indígenas correspondientes sobre la modificación realizada en la integración del Consejo Consultivo, en contravención a lo dispuesto tanto por la Carta Magna como por el tratado internacional antes mencionado.

En este contexto, la SCJN dio inicio al estudio del fondo del asunto reconociendo que, como se ha expuesto en apartados precedentes, los pueblos indígenas cuentan con el derecho a que se les consulte de manera previa, mediante procedimientos culturalmente adecuados, informados, de buena fe, a través de sus representantes y con el propósito de llegar a un acuerdo, cuando se prevean, como en este caso, medidas legislativas susceptibles de afectarlos directamente. ${ }^{43}$

En este sentido, procedió a analizar si para emitir la disposición impugnada debió haberse consultado a las comunidades indígenas con presencia dentro del Consejo Consultivo del INDEPI.

Para ello, revisó la naturaleza y funciones del mencionado Consejo Consultivo, asentando que, además de fungir como promotor de las acciones del Instituto, constituye un órgano representativo de los pueblos indígenas, asesor en materia de cultura y derechos indígenas en torno a las políticas públicas o medidas que adopten los demás órganos que integran el INDEPI. 44

Asimismo, manifestó que el Consejo Consultivo permite que las comunidades indígenas ejerzan "su derecho a participar en el diseño de las políticas públicas que se adoptarán por parte del Poder Ejecutivo

42 El contenido de ambos preceptos ha sido transcrito en el apartado IV de este ensayo. El texto completo de la demanda de inconstitucionalidad presentada por la mencionada Comisión Estatal puede verse en: www.cedhs/p.org.mx/Boletines/140731\%20accion\%20 de\%20inconstitucionalidad.pdf.

43 SCJN, sentencia dictada en la acción de inconstitucionalidad 31/2014, 8 de marzo de 2016, p. 20. El texto completo de la sentencia, incluyendo el de los votos concurrentes de los ministros Alfredo Gutiérrez Ortiz Mena, Arturo Zaldívar Lelo de Larrea y José Ramón Cossío Díaz, puede verse en: www2.scjn.gob.mx/ConsultaTematica/PaginasPub/Detalle Pub.aspx?AsuntolD $=167731$.

44 Ibidem, p. 21. 
Esta revista forma parte del acervo de la Biblioteca Jurídica Virtual del Instituto de Investigaciones Jurídicas de la UNAM

EL DERECHO A LA CONSULTA DE LOS PUEBLOS INDÍGENAS...

local con la finalidad de lograr una sociedad más justa, igualitaria, responsable, libre y democrática". ${ }^{45}$

Entre las funciones específicas del Consejo destacan las siguientes: asesorar a la Junta Directiva, así como al director del Instituto en la formulación de políticas, planes y programas de su competencia; proponer medidas que impulsen y favorezcan la participación de los sectores interesados en las acciones que lleva a cabo el Instituto; proponer y dar seguimiento a las políticas, programas, proyectos, indicadores y acciones emprendidas por el Instituto, planteando, en su caso, las modificaciones que estime pertinentes con el fin de perfeccionarlas; plantear ante el Instituto, para su atención, problemas que deriven de situaciones de discriminación o inequidad relacionadas con las comunidades e individuos indígenas del estado; y promover el respeto a la diversidad cultural en el estado. 46

Como puede verse, el Consejo Consultivo se erige como un órgano de naturaleza propositiva (no decisoria, ya que ello corresponde a la Junta Directiva como órgano de gobierno del INDEPI) en el que las comunidades indígenas del estado, a través de sus representantes, tienen la posibilidad de exponer sus posturas y debatir en torno a las distintas políticas y acciones que desee emprender el Instituto.

Para decirlo de manera distinta, el Consejo es el órgano que sirve como vía para que las comunidades indígenas, mediante sus representantes, participen e incidan sobre el actuar de los demás órganos que integran el Instituto, emitiendo opiniones y propuestas al respecto. Luego, en virtud de la estrecha cercanía que poseen las comunidades con el Consejo Consultivo, resulta indudable que toda medida que modifique o altere la naturaleza, estructura o funciones de éste interesa a dichas comunidades, al ser susceptible de causarles un perjuicio directo, tal como lo reconoció la SCJN. ${ }^{47}$

En el caso particular, la sola incorporación de determinados diputados locales en la estructura del Consejo Consultivo a partir de la emisión de la norma impugnada se traduce en una medida legislativa que impacta directamente en los intereses de las comunidades indígenas representadas en dicho órgano, y que, por ende, resulta de su total incumbencia.

Ello resulta lógico, debido a que con esa medida se altera la forma de adoptar las determinaciones dentro del Consejo Consultivo, puesto

\section{Ibidem, p. 25.}

46 Las atribuciones del Consejo Consultivo se encuentran enunciadas en el artículo 30 de la Ley para el INDEPI, norma disponible en: www.ordenjuridico.gob.mx/fichaOrdena miento.php?idArchivo $=95984 \&$ ambito $=$ estatal.

47 SCJN, sentencia dictada en la acción de inconstitucionalidad 31/2014, pp. 26 y 27. 
Esta revista forma parte del acervo de la Biblioteca Jurídica Virtual del Instituto de Investigaciones Jurídicas de la UNAM

\section{JUAN ÁNGEL ARROYO KALIS}

que no serán solamente los representantes indígenas quienes decidirán a través de su voto, sino que también habrá que tomarse en cuenta el voto de cada uno de los legisladores locales que se sumen al mismo, quienes, sobra decirlo, poseen enfoques particulares y agendas propias sobre los temas que se aborden en el seno del Consejo Consultivo.

En consecuencia, es innegable que antes de expedir la norma en cuestión debió consultarse a las comunidades indígenas sobre la modificación en la integración del Consejo Consultivo. Dicho de otro modo, durante el proceso legislativo debió llevarse a cabo la consulta con los representantes de las comunidades indígenas, al tratase de una medida legislativa que les afectaba directamente.

Por ello, la SCJN determinó, con razón, que "el procedimiento legislativo por el cual se emitió la adición al artículo impugnado es contrario al derecho de consulta previa que tienen los pueblos y comunidades indígenas". 48

Así, por mayoría de ocho votos de los ministros presentes, se resolvió declarar la invalidez del párrafo quinto del artículo 27 de la Ley para el INDEPI, pues el procedimiento en virtud del que se adoptó esta medida legislativa incumplió lo previsto en la Constitución federal y en el Convenio 169 de la OIT en materia de derecho a la consulta de los pueblos y comunidades indígenas.

La sentencia concluye con los votos concurrentes de los ministros Alfredo Gutiérrez Ortiz Mena, Arturo Zaldívar Lelo de Larrea y José Ramón Cossío Díaz. Para efectos de este trabajo, interesa destacar algunos pasajes del voto del último de los jueces constitucionales mencionados, en tanto que guarda relación con los alcances que debió poseer el fallo bajo estudio.

Para Cossío Díaz es incorrecto que la declaratoria de invalidez se hubiese ceñido a la norma impugnada, ya que, en su opinión, también debió comprender el artículo 9, fracción IV, de la Ley de Consulta Indígena para el Estado y Municipios de San Luis Potosí, cuyo texto dispone que serán objeto obligado de consulta las iniciativas de ley o de reforma de ley en materia indígena, "con excepción de las relativas a la materia fiscal y presupuestaria, así como las que se refieran a adecuaciones de normas ya previstas, o cuando sean notoriamente improcedentes".

Lo anterior, en razón de que el Congreso local de San Luis Potosí argumentó, durante la tramitación de la acción de inconstitucionalidad, que la disposición impugnada era justamente una adecuación de la Ley para el INDEPI a lo previsto en el artículo 12, fracción IV, de la Ley de la

48 Ibidem, p. 29. 
Esta revista forma parte del acervo de la Biblioteca Jurídica Virtual del Instituto de Investigaciones Jurídicas de la UNAM

EL DERECHO A LA CONSULTA DE LOS PUEBLOS INDÍGENAS...

Comisión Nacional para el Desarrollo de los Pueblos Indígenas (publicada en el Diario Oficial de la Federación el 21 de mayo de 2003). ${ }^{49}$ A decir del Congreso local, existía justificación para haber omitido la consulta a las comunidades indígenas correspondientes en este asunto.

Al respecto, el ministro advirtió en el presente caso "una relación de dependencia material de validez entre estas dos normas, en la que la invalidez directa de una afecta a otra de su misma jerarquía, debido a que ésta regula alguna cuestión prevista en aquélla". Por tanto, "debió declararse la invalidez indirecta de la fracción IV del artículo 9 de la Ley de Consulta Indígena para el Estado y Municipios de San Luis Potosí, pues materialmente la norma impugnada depende de ella, por lo que debieron extenderse los efectos de [la] declaratoria a ésta también". ${ }^{50}$

$\mathrm{Se}$ trata de una postura acertada. En defensa del orden constitucional es indispensable que los efectos de una sentencia estimatoria o declarativa de inconstitucionalidad se extiendan a todas aquellas normas cuya validez dependa de la norma impugnada, o que regulen o posean relación directa con algún aspecto de la misma. Si esto no fuese así, la efectividad del control constitucional que se ejerce a través de la acción de inconstitucionalidad se vería severamente disminuida al dejar intocadas ( $\mathrm{y}$, por tanto, vigentes) disposiciones contrarias a la Constitución por el hecho de no haber sido impugnadas o combatidas por el órgano competente para ello. Como bien sostiene Hans Kelsen, "[u]na Constitución en la que los actos inconstitucionales y en particular las leyes inconstitucionales se mantienen válidos - sin poder anular su inconstitucionalidad- equivale más o menos, desde un punto de vista estrictamente jurídico, a un deseo sin fuerza obligatoria". ${ }^{51}$

Sobre este tema, conviene citar la siguiente tesis de jurisprudencia, en cuyo texto se explican los alcances que posee la figura de la invalidez extensiva en el marco de la acción de inconstitucionalidad:

ACCIÓN DE INCONSTITUCIONALIDAD. EXTENSIÓN DE LOS EFECTOS DE LA DECLARACIÓN DE INVALIDEZ DE UNA NORMA GENERAL A OTRAS QUE, AUNQUE NO HAYAN SIDO IMPUGNADAS, SEAN DEPENDIENTES DE AQUÉLLA. Conforme al artículo 41, fracción IV, de la Ley Reglamentaria de las Fracciones I y II del

49 Dicho precepto establece, en su parte conducente, lo siguiente: "La Comisión [Nacional para el Desarrollo de los Pueblos Indígenas] contará con un Consejo Consultivo, integrado por: ...IV. Los integrantes de las mesas directivas de las Comisiones de Asuntos Indígenas de ambas Cámaras del Congreso de la Unión...".

50 Voto concurrente del ministro José Ramón Cossío Díaz en la sentencia de la acción de inconstitucionalidad 31/2014, p. 5.

51 Kelsen, Hans, La garantía jurisdiccional de la Constitución (la justicia constitucional), México, UNAM, Instituto de Investigaciones Jurídicas, 2016, p. 95. 
Esta revista forma parte del acervo de la Biblioteca Jurídica Virtual del Instituto de Investigaciones Jurídicas de la UNAM

\title{
JUAN ÁNGEL ARROYO KALIS
}

\begin{abstract}
Artículo 105 de la Constitución Política de los Estados Unidos Mexicanos la Suprema Corte de Justicia de la Nación, al declarar la invalidez de una norma general, deberá extender sus efectos a todas aquellas normas cuya validez dependa de la propia norma invalidada, sean de igual o menor jerarquía que la de la combatida, si regulan o se relacionan directamente con algún aspecto previsto en ésta, aun cuando no hayan sido impugnadas, pues el vínculo de dependencia que existe entre ellas determina, por el mismo vicio que la invalidada, su contraposición con el orden constitucional que debe prevalecer. Sin embargo, lo anterior no implica que este Alto Tribunal esté obligado a analizar exhaustivamente todos los ordenamientos legales relacionados con la norma declarada inválida y desentrañar el sentido de sus disposiciones, a fin de determinar las normas a las que puedan hacerse extensivos los efectos de tal declaración de invalidez, sino que la relación de dependencia entre las normas combatidas y sus relacionadas debe ser clara y se advierta del estudio de la problemática planteada. 52
\end{abstract}

En opinión de Cossío Díaz, la inconstitucionalidad de la fracción IV de artículo 9 de la Ley de Consulta Indígena para el Estado y Municipios de San Luis Potosí radica fundamentalmente en el hecho de que no se observa disposición alguna en la Constitución federal ni en el Convenio 169 de la OIT que limite o acote las materias sobre las cuales se deba llevar a cabo una consulta en aquellos asuntos que afecten a las comunidades indígenas. En tal orden, se señaló que la función del legislador local "no tiene el alcance de determinar que ciertos temas no deben ser consultados [...] ya que no existe fundamento constitucional para tal restricción". 53

Sobre este punto, cabe reiterar que la Constitución prevé el ejercicio del derecho a la consulta únicamente en el procedimiento de elaboración del Plan Nacional de Desarrollo, así como de sus equivalentes en el ámbito de las entidades federativas y municipios, cuestión que amerita corregirse a la brevedad; empero, el Convenio 169 de la OIT (que forma parte del orden jurídico nacional y que, en esa condición, debe ser acatado) ${ }^{54}$ ordena que la consulta se efectúe en cada ocasión en la

52 Tesis P./J. 32/2006, Semanario Judicial de la Federación y su Gaceta, Novena Época, t. XXIII, febrero de 2006, p. 1169 (énfasis añadido).

53 Voto concurrente del ministro José Ramón Cossío Díaz en la sentencia de la acción de inconstitucionalidad 31/2014, pp. 6 y 7.

54 A mayor abundamiento, el artículo 10. constitucional dispone, en su primer párrafo, que en el territorio nacional las personas gozan de los derechos humanos reconocidos no sólo en la propia Constitución, sino también en los tratados internacionales de los que el Estado mexicano forme parte. 
Esta revista forma parte del acervo de la Biblioteca Jurídica Virtual del Instituto de Investigaciones Jurídicas de la UNAM

EL DERECHO A LA CONSULTA DE LOS PUEBLOS INDÍGENAS...

que un Estado parte pretenda adoptar cualquier medida legislativa o administrativa que pueda afectar de forma directa a los pueblos indígenas sujetos a su jurisdicción.

En este contexto, una ley secundaria no puede reducir o aminorar los alcances de un tratado internacional, como sucede en la especie. Como se sabe, los Estados, en ejercicio de su soberanía, contraen obligaciones en distintas materias a través de la firma y ratificación de tratados internacionales; obligaciones que no se pueden desconocer o incumplir invocando disposiciones de derecho interno. ${ }^{55}$ Las normas secundarias de un país, en todo caso, deben desarrollar y ampliar los alcances de esos tratados internacionales en beneficio de los derechos de las personas.

Por lo anterior, se estima que la SCJN debió extender los efectos de la declaratoria de inconstitucionalidad a la referida fracción IV del artículo 9o. de la Ley de Consulta Indígena de San Luis Potosí, argumentando que dicha disposición contradice lo previsto en el Convenio 169 de la OIT, que, como se dijo, obliga a los Estados parte a consultar a los pueblos indígenas cada vez que se desee ejecutar una medida legislativa o administrativa que pueda afectarlos de manera directa, sin que dicha consulta se limite o restrinja a determinados temas o materias.

\section{CONSIDERACIONES FINALES}

El propósito de este ensayo ha sido exponer los principales elementos del derecho a la consulta de los pueblos indígenas a fin de evidenciar la importancia que representa para dicho grupo vulnerable.

El derecho a la consulta contribuye a salvaguardar los derechos e intereses de los pueblos indígenas y, al mismo tiempo, incentiva que las decisiones públicas que involucren a ese sector social gocen de mayor legitimidad, al ser éstas producto de un proceso de diálogo y concertación. De esta manera, se abona, en gran medida, a la consolidación del régimen democrático en el país.

De ahí la importancia de la sentencia que se revisa en este ensayo, en la que, a través de la preservación del orden constitucional, se protege el derecho a la consulta indígena ante extralimitaciones del poder público que lo transgreden, garantizando su ejercicio cuando éste resulta procedente.

55 Se trata del conocido principio internacional pacta sunt servanda; véanse, en este orden, los artículos 26 y 27 de la Convención de Viena sobre el Derecho de los Tratados de 1969. 
Esta revista forma parte del acervo de la Biblioteca Jurídica Virtual del Instituto de Investigaciones Jurídicas de la UNAM

\section{JUAN ÁNGEL ARROYO KALIS}

Así, se impulsa que los pueblos indígenas transiten progresivamente hacia un estado de bienestar y desarrollo, involucrándose en todas aquellas decisiones públicas que puedan afectar su forma de vida, para superar la situación de exclusión e indefensión en la que permanecen desde hace varias décadas en el país.

\section{BiBLiografíA}

ANAYA, James, Los pueblos indígenas en el derecho internacional, Madrid, Trotta, UNIA, 2005.

CARPIZO, Jorge, "Una clasificación de los derechos de la justicia social", en BogdANDY, Armin von et al. (coords.), Construcción y papel de los derechos sociales fundamentales. Hacia un ius constitutionale commune en América Latina, México, UNAM, Instituto de Investigaciones Jurídicas, Max-Planck-Institut für ausländisches öffentliches Recht und Völkerrecht, Instituto Iberoamericano de Derecho Constitucional, 2011.

GonZÁleZ GalvÁN, Jorge Alberto, "Derecho indígena: consulta y participación ciudadana", en CARBONELL, Miguel y CRUZ BARNEY, Oscar (coords.), Historia y Constitución. Estudios en homenaje a José Luis Soberanes Fernández, México, UNAM, Instituto de Investigaciones Jurídicas, 2015, t. I.

GUTIÉRREZ RIVAS, Rodrigo, "Derecho a la consulta de los pueblos indígenas en México: un primer acercamiento", en FERRER MAC-GREGOR, Eduardo y ZALDívAR LeLO DE LARREA, Arturo (coords.), La ciencia del derecho procesal constitucional. Estudios en homenaje a Héctor FixZamudio en sus cincuenta años como investigador del derecho, México, UNAM, IMDPC, Marcial Pons, 2008, t. XII: Ministerio público, contencioso administrativo y actualidad jurídica.

KELSEN, Hans, La garantía jurisdiccional de la Constitución (la justicia constitucional), 1a. reimp., México, UNAM, Instituto de Investigaciones Jurídicas, 2016.

NogueiRA AlCALÁ, Humberto, La jurisdicción constitucional y los tribunales constitucionales de Sudamérica en la alborada del siglo XXI, México, Porrúa, IMDPC, 2004.

Romero Pérez, Xiomara y Rosas Martínez, Alejandro, "Implementación de la consulta previa en Colombia y su debate actual. A propósito de los pueblos indígenas y tribales", en MACíAS VÁZQUEZ, María del Carmen y ANGLÉs HERNÁNDEZ, Marisol (coords.), Estudios en homenaje a don José Emilio Rolando Ordóñez Cifuentes, México, UNAM, Instituto de Investigaciones Jurídicas, 2013. 
Esta revista forma parte del acervo de la Biblioteca Jurídica Virtual del Instituto de Investigaciones Jurídicas de la UNAM

EL DERECHO A LA CONSULTA DE LOS PUEBLOS INDÍGENAS...

RuIz, Oswaldo y GINA, Donoso, "Pueblos indígenas y la Corte Interamericana de Derechos Humanos. Fondo y reparaciones", en STEINER, Christian y URIBE, Patricia (eds.), Convención Americana sobre Derechos Humanos. Comentario, Montevideo-Berlín, Fundación Konrad Adenauer, 2014.

SAGÜÉS, Néstor Pedro, La Constitución bajo tensión, México, Instituto de Estudios Constitucionales del Estado de Querétaro, 2016.

VILLAVERDE MENÉNDEZ, Ignacio, "La resolución de conflictos entre derechos fundamentales. El principio de proporcionalidad", en VARIOS AUTORES, El principio de proporcionalidad y la interpretación constitucional, Quito, Ministerio de Justicia y Derechos Humanos, 2008. 